Background Although Hydatid liver disease may be asymptomatic, one complication of Hydatid disease is perforation of the cyst into the peritoneal cavity after trauma. We present herein a case presented after trauma and had a diagnosis of Hydatid cyst rupture into the peritoneum previously asymptomatic boy.

Case A 7-year-old boy presented with mild abdominal pain for $6 \mathrm{~h}$. His parents told that his abdominal pain was suddenly commenced after falling down from swing when playing at the playground. They also complained of itching on the whole body starting soon after the trauma. His blood pressure was 90/60 $\mathrm{mmHg}$, heart rate $118 / \mathrm{min}$, and temperature $37.0^{\circ} \mathrm{C}$. On the physical examination, urticaria was seen over the thigh and trunk, abdominal examination revealed generalised tenderness. Ultrasonography and computed tomography showed multiple cystic lesions in the liver and one of them had hypoechoic contents and floating echogenic membranesand also free fluid were seen in the pelvis. Intravenous fluids were started followed Hydrocortisone and antihistamine administered along with antibiotic prophylaxis. The patient underwent surgery, 3 cysts at different localization and also a ruptured cyst $4 \mathrm{~cm}$ in diameter at the segment 1 were seen. The germinative membranes and the daughter vesicles were removed and abdomen was irrigated with hypertonic saline $(3 \% \mathrm{NaCl})$. Postoperative albendazole therapy was given for two months.

Conclusion Rupture of Hydatid cyst should be considered in the differential diagnosis at the presentation of acute abdominal findings with urticaria after abdominal blunt trauma. US and CT are effective in diagnosing of this rare condition.

\section{P0-0907 A CASE OF BACK TO THE FUTURE: PAEDIATRIC ABDOMINAL PAIN. THOROUGH HISTORY, EXAMINATION AND SENIOR CLINICIAN INVOLVEMENT REMAIN IMPERATIVE FOR SUCCESSFUL MANAGEMENT}

${ }^{1} \mathrm{C}$ Beardsley, ${ }^{2} \mathrm{~A}$ Dillon, ${ }^{2} \mathrm{M}$ Chiu, ${ }^{3} \mathrm{~F}$ Nguyen, ${ }^{3} \mathrm{GDH}$ Croaker. ${ }^{1}$ General Surgery, Canberra Hospital, Canberra, Australia; ${ }^{2}$ Medical School, Australian National University, Canberra, Australia; ${ }^{3}$ Canberra Hospital, Dpt Paediatric Surgery, Canberra, Australia

\subsection{6/archdischild-2014-307384.1529}

Introduction The inherent variability of the history and exam inpaediatrics make acute abdominal pain a diagnostic challenge. Investigations such as white-cell-count (WCC), C-reactive-protein and radiological studies have been advocated tohelp objectify management. Whilst Computed Tomography is accurate, the amount ofradiation involved renders it unacceptable and thus many view ultrasonographyas an acceptable alternative. But do these tests add value?

Methods Retrospective review between 2002-2012. Data was collected for children under sixteen with acute abdominal pain undergoinginvestigation with ultrasound and haematological testing. For 2005, a retrospective review was conducted for children presenting with abdominalpain to obtain data on demographics, history and examination findings. Analysis for diagnostic accuracy was undertaken.

Results 5000 records were reviewed, and 1744 records included. $6 \%$ of children developed appendicitis. Findingsof worsening pain, associated with nausea or vomiting yielded moderatesensitivities and specificities (combined values over $70 \%$ ). Fever was non-specific. Localised tenderness is the most sensitiveexam finding and rebound tenderness is the most specific, both having values over 90\%. WCC and CRP offer similar sensitivitiesand specificities, both producing results under $80 \%$. Only $30 \%$ of ultrasounds visualisedthe appendix, significantly dampening the sensitivity below $75 \%$. The incidence of appendicitis in thenon-visualised group was $8 \%$.

Conclusion No test is useful for ruling out appendicitis. Given thatthe incidence of appendicitis is higher in the non-visualised group, this isespecially so with ultrasonography. Clinical examination with senior input isthe most sensible strategy for managing children with acute abdominal pain.

\section{PO-0908 EXTERNAL INFLUENCES ON PAEDIATRIC ABDOMINAL PAIN: A HOLISTIC VIEW MAY HELP}

${ }^{1} \mathrm{C}$ Beardsley, ${ }^{2} \mathrm{G}$ Melino, ${ }^{2} \mathrm{GDH}$ Croaker. ' General Surgery, Canberra Hospital, Canberra, Australia; ${ }^{2}$ Paediatric Surgery, Canberra Hospital, Canberra, Australia

\subsection{6/archdischild-2014-307384.1530}

Introduction Abdominal pain should always be treated as aserious complaint by the clinician due to the large proportion of potentiallyserious medical conditions which can present with abdominal pain. However, a large proportion of children will not haveany significant disease processes underway. This study focuses on extrinsicfactors which may be associated with abdominal pain presentations to helpelucidate appropriate management.

Methods Prospective study. A survey was administered to children and their parents, presenting tocasualty for assessment of abdominal pain. Questions related to thepatient and their family. Information obtained related to the child'shealth, social/family dynamics and family history wereobtained.

Results 97 surveys were conducted. There was an equal sex distribution. Mean age was11. The three most common diagnoses were of Benign pain, Mesenteric adenitisand Appendicitis. There was a peak in winterpresentations for those with benign pain. $27 \%$ of children with benign pain had parentswho smoked. Inflammatory conditions were common with $38 \%$ and $28 \%$ of children, having family histories of asthma and eczema respectively. 9\% had a history of IBS and Coeliac disease. Nodifferences between the sexes were observed.

Conclusion Children presenting to hospital with abdominal pain have a higher prevalence ofparental smoking, eczema, asthma and migraine. There is a peak incidence inbenign presentations during winter. Even in children with significantextrinsic influences, appendicitis was the third most common diagnosis, mandating thorough evaluation for all children with abdominal pain nomatter the background circumstances.

\section{PO-0909 WITHDRAWN}

\section{PO-0910 LAPAROSCOPIC INGUINAL HERNIA REPAIR IN CHILDREN: CLINICAL EVALUATION OF 46 CASES}

C Berghea Neamtu. Pediatric Surgery, Pediatric Clinic Hospital, Sibiu, Romania

\subsection{6/archdischild-2014-307384.1531}

Background Laparoscopic inguinal hernia repair in children tend to be performed routinely, with some advantages compared to conventional repair.

Aims The paper aims to assess the cases of inguinal hernia repair by laparoscopic procedure in 2 clinics of paediatric surgery from the country in the last 3 years. 